\title{
REFLEXÕES SOBRE A MOEDA SOCIAL E SEU PODER DE COMERCIALIZAÇÃO EM COMUNIDADES
}

\author{
Bruno Silvestre Silva de Souza ${ }^{1}$ \\ Marcelo Pereira Souza ${ }^{2}$
}

\begin{abstract}
RESUMO
O ponto de partida deste trabalho deu-se pela compreensão da moeda social como um instrumento de construção econômico-social em comunidades brasileiras, dada a sua repercussão quanto ao aumento da circulação da moeda entre as práticas de compra e venda no país. Concentramo-nos, portanto, nas contribuições da sociologia econômica para refletir sobre o papel econômico e de racionalização da vida social tradicionalmente retratada nos estudos sobre as moedas, para propor um olhar de fortalecimento social em comunidades que aderiram a esse instrumento como ferramenta de barganha. Para conseguir apresentar à temática, buscaremos discorrer como a circulação da moeda social contribui para a (re) configuração de uma economia local, bem como dialogar sobre seu papel na inclusão do indivíduo no processo econômico, discursando, ainda, sobre os reflexos e custo real de sua produção cultural. Não obstante, traremos ao palco das reflexões teóricas, aqui propostas, a simbólica catalogação das 103 moedas existentes e em circulação no Brasil - dados divulgados pela Secretaria Nacional de Economia Solidária - para corroborar com a importância de se notabilizar sobre o fenômeno da moeda social no cenário sociológico contemporâneo. A metodologia utilizada para desenvolver este trabalho é a revisão de literatura. Para tanto, foram consultadas, obras de autores representantes da sociologia econômica e da economia solidária para justificar a escolha pela temática aqui proposta, bem como embasá-la e discuti-la de acordo com o pensamento social.
\end{abstract}

Palavras-chave: Moeda Social. Sociologia Econômica. Comunidades.

\section{REFLECTIONS ON THE SOCIAL CURRENCY AND ITS MERCHANTABILITY IN COMMUNITIES}

\begin{abstract}
The starting point for this work was the understanding of the social currency as an instrument of economic-social construction in Brazilian communities, given its repercussion on the increase in the circulation of money between buying and selling practices in the country. We focus, therefore, on the contributions of economic sociology to reflect on the economic role and rationalization of social life traditionally portrayed in the studies on currencies, to propose a look of social strengthening in communities that have adhered to this instrument as a bargaining tool. In order to be able to present the theme, we will discuss how the circulation of the social currency contributes to the (re) configuration of a local economy, as well as to discuss its role in the inclusion of the individual in the economic process, also discoursing on the reflexes and real cost of its cultural production. Nonetheless, we will bring to the stage of the theoretical reflections proposed here the symbolic
\end{abstract}

\footnotetext{
1 Mestre em Consumo, Cotidiano e Desenvolvimento Social pelo Programa de Pós-Graduação em Consumo, Cotidiano e Desenvolvimento Social da Universidade Federal Rural de Pernambuco. Email: brunosilvestre@yahoo.com.br

2 Mestrando em Sociologia pelo Programa de Pós-Graduação em Sociologia da Universidade Federal de Sergipe. E-mail: marcelo_souzaadm@yahoo.com.br.
} 
cataloging of the 103 existing and circulating currencies in Brazil - data released by the National Secretariat for Solidarity Economy - to corroborate the importance of noting about the phenomenon of social currency in Brazil. contemporary sociological setting. The methodology used to develop this work is the literature review. In order to do so, we consulted the works of authors representing economic sociology and solidarity economy to justify the choice of the theme proposed here, as well as to base it and discuss it according to social thought.

Keywords: Social Currency. Economic Sociology. Communities.

\section{INTRODUÇÃO}

Esse artigo começa a sua reflexão sobre a moeda social e seu poder de comercialização nas comunidades na formação histórica abordada o livro $O$ Jogo das Trocas de Fernand Braudel quando reflete sobre o Modo de Produção Capitalista, retomando costumes, processos, mercado, trabalho e sistemas do mundo.

Braudel (2005) transcorre com fenômenos sociais, o conceito de experiência, cita Bourdieu e Foucault, a dimensão do simbólico e sua relação com a formação dos mercados, a existência de relações entre as Classes x Formação histórica descritiva e Subordinação de Trabalho.

Braudel (2005) aparece com uma questão de uma circulação, pelo contrário, tem a vantagem de ser de fácil observação. Pois, a produção é a divisão do trabalho, portanto, obrigatoriamente, a condenação dos homens à troca é um complemento. Quando o autor começa a falar dos Instrumentos de Troca, ele cita o início das trocas monetárias sociais com as Feiras e o ambiente da Classe social, uma vez que a desonestidade burguesa em busca de algo para comprar, criadas que são hábeis "em passar a perna" (dizem os ricos) nos patrões quanto ao preço. Por isso, a criação social de uma moeda social, para estabelecer uma relação comercial de confiança na sua comercialização. Braudel cita que essa atitude deu origem a um crédito social.

Braudel (2005) se situa numa relação com Marx (1985) a separação entre produção e venda quando ele menciona que as feiras urbanas são realizadas geralmente uma ou duas vezes por semana. Para abastecê-las, é necessário que o campo tenha tempo de produzir e reunir os gêneros e possa dispensar uma parte da sua mão-de-obra para venda. Ele cita até a origem do Pescado o tempo para pescar 
e as vendas nos mercados, as feiras. Uma visão contra o capitalismo que veio depois de Marx onde não se gasta mais do que se tem.

Braudel volta a Marx (1985) quando ele cita que o dinheiro no campo, raramente é capital. À medida que a economia mercantil se espalha e chega até as áreas vizinhas e inferiores, os mercados se ampliam e andam até a fronteira, na área rural e empregada nas compras de terras e através dessas compras visa à promoção social, que aguarda semelhança com Freyre (1987) quando fala sobre a o lado de se promover e conseguir se dar bem na sociedade e conseguir um sucesso.

\section{A ILUSÃO ECONÔMICA DO CAPITALISMO}

Thompson (2011) que afirmou quer apesar da forte presença do econômico, o simbólico tem sua importância na difusão da cultura de classe e dialoga também com Braudel (2005) que afirma a existência da dimensão do simbólico e sua relação com a formação dos mercados (lado econômico e lado cultural existindo ao mesmo tempo).

Nos seus estudos sobre o Desenvolvimento do Capital Mandel (1968) fez uma Narrativa da Formação da Família, e entre outros aspectos, ele cita a influência da Família Colonial (no período de mesmo nome), outro autor Certeau (1994) volta a esse aspecto quando menciona o "enigma do consumidor-esfinge", quando a fabricação de seus produtos não tem espaço nas organizações colonizadas para os consumidores marcarem sua atividade.

Não se deve surpreender o fato de que Marx (1985) era um leitor atento de Adam Smith, embora dificilmente um celebrante do comércio ou dos comerciantes. Na juventude, Marx admirava pelo menos a teoria geral da espontaneidade em $A$ teoria dos sentimentos morais, como analista mais adulto e sóbrio, concentrou-se na descrição por Smith dos males da rotina, divisão do trabalho sem o controle do trabalho pelo trabalhador - estes são os ingredientes essenciais da análise marxista do tempo transformado em produto.

Em contraste, como escreveria mais tarde 0 historiador marxista Thompson (2011), no capitalismo moderno os empregados "sentem uma distinção entre o tempo do patrão e o seu 'próprio' tempo". 
Refraseando essa crítica da rotina, a atividade mecânica não gera um senso de narrativa histórica maior: as micronarrativas na vida de trabalhadores como pareceram a Marx (1985) negligenciáveis na escala maior da História, ou meras acomodações a circunstâncias existentes.

A visão marxista (1985) tradicional da consciência de classe se baseia no processo de trabalho, especificamente em como os trabalhadores se relacionam uns com os outros através do seu trabalho.

Para Singly (2012) a visão moderna da transição do século XIX para o XX o Estado passa a ser substituto econômico do marido, o Estado começou a intervir na família moderna. Hoje, o Estado regula a esfera privda por meio de varios procedimentos. Esse mesmo Estado atua no nível jurídico, no nível institucional, entretanto neste artigo a preocupação é com o nível econômico, com a previdência social, as aposentadorias, o incentivo à poupança, por meio de certas ajudas como os abonos para pai/mãe sozinho, por meio do fisco;

Para Commaile (1991), o objetivo não é pressionar nas escolhas na orientação dos comportamentos, orientando os privados, porém sem nunca se curvar cada vez mais aos efeitos sociais, às situações sociais que decorrem dessas escolhas anteriormente citadas.

Singly (2012: 65) afirma que o Estado passa a ser avalista da individualização, esse pensamento foi substanciado anteriormente por Duckenheim (1950) quando afirmou que o papel do Estado não tem nada de negativo, ele (o Estado) visa manter a indivdualização por completa no seu papel social. O Estado não ocupa um papel tirano e sim aquele que libera o indíviduo da sociedade formalmente organizada. Esse pensamento corrobora a criação das moedas sociais, pois o Estado está liberando o individuo ou a individualização.

\section{EM PROL DE UMA ECONOMIA SOLIDÁRIA}

Com o advento crescente do capitalismo nas últimas décadas, a onda de competitividade oriunda do capitalismo tem contribuído para o crescente aumento da desigualdade social, principalmente entre as camadas mais vulneráveis da sociedade. Apesar da existência de um crescente desenvolvimento econômico em 
uma dada região, a distribuição de renda, ainda, continua sendo alvo de distribuição desigual perante a sua população, o que por sua vez, recai no desencadeamento das desigualdades sociais. Então, eis que surge uma alternativa para a população que mais sofre com as desigualdades existentes no sistema capitalista: a economia solidária (DAMASCENO; GUEDES; JÚNIOR; SOUZA, 2016).

A economia solidária ou economia social, tem seu nascituro em face das crises empresariais, do desemprego e da exclusão social em que vivemos, sendo ela um projeto econômico que busca a geração de igualdade e oportunidade para todos (MIRANDA, 2008). Para Singer (2002), por proporcionar uma melhor qualidade de vida aos seus participantes, inserindo-os no bojo da cooperação e não da competição, a economia solidária seria uma alternativa propensa para superar o capitalismo.

Na recente economia cunhada, o termo "solidária" fundamenta-se na tese das contradições postas pelo capitalismo que afirma criar oportunidades de desenvolvimento econômico, no entanto, diferentemente da sociedade de mercado, a lógica produtora da economia solidária opõe-se à produção dominante (SINGER, 2002). De certo, desde os idealizadores desse modelo experimental, até 0 atingimento de seus demais participantes, compreende-se tal processo como uma recolocação econômica que se integra a finalidade social, ao reintegrar aqueles indivíduos pertencentes a circulação monetária à esfera sociocultural (MIRANDA, 2009).

Teria, a criação da economia solidária, como propósito, ir além do objetivo de uma inclusão social por meio de uma "produção maior e mais descentralizada", a ideia de ajudar os "despossuídos" parte de uma analogia que tende a transmutar a instituição financeira como uma instituição monetária social completa, a partir das apreensões no sistema econômico dominante, no qual, a existência de uma arena de disputas de poder econômico inclina-se a beneficiar uns mais que os outros, gerando, portanto, mais desigualdades (SOARES, 2011).

A economia solidária "em cada região ou país assume diferentes conceitos, de acordo com a realidade estabelecida, além disso, é marcada por formas inéditas de ação pública, nas relações com o Estado e a sociedade civil organizada (MIRANDA, 2008). Por isso, a associação junto a economia solidária ocorre entre aqueles que compartilham dos mesmos valores (SOARES, 2011). Para 
tanto, tais façanhas são concretizadas quando as relações de poder que comandam as atividades mercantis são demarcadas, pois, é a partir do enfrentamento desse modelo econômico tradicional que os moldes da economia podem ser reinventados (BLANC, 1998).

Segundo Miranda (2008), quanto a lógica da economia solidária:

Tem sua origem vem do desemprego e da precarização do trabalho. Surgem daí empreendimentos auto gestionários e cooperativas de trabalhadores complementando o sistema socioeconômico presente, ou até mesmo formando um novo sistema. Como conjunto de atividades para produção e distribuição de riquezas é economia, mas é solidária por ter este objetivo de ter as atividades econômicas como um meio para a realização e consecução de outros ganhos de natureza social, política e cultural (p.3).

Através do emprego da economia solidária é possível elaborar modelos de desenvolvimentos autônomos, diferenciando-se dos modelos tradicionais aplicados no país, ao envolver novas experiências monetárias diferentes daquelas estimuladoras pelos valores sociais individualizados e do forte estímulo da concorrência, tratando-se de "uma forma de reorientar os objetivos do novo desenvolvimento pretendido" (SOARES, 2011). Dessa forma, a economia solidária produz domesticidade, é recíproca nos reforços das trocas sociais, redistribuidora de bens e serviços, e fortalecedora de laços de solidariedade (POLANY, 1980).

[...] As iniciativas de Economia Solidária são expressões de práticas sociais comuns aos grupos excluídos pela lógica do capital, os quais se organizam localmente, segundo suas condições materiais de subsistência, para lutar pelo desenvolvimento de sua qualidade de vida (MELO, 2004, p. 521).

Tão logo, o capital social pode ser visto como um processo de aprendizado que se dá nas interações informais ou estruturadas durante o processo de interação e de mudança em uma comunidade (MACIEL, 2008). Por meio da economia solidária é possível recuperar 0 sentido social da economia, enfrentamento a desigualdade, a pobreza e a exclusão. Por meio desse enfoque, o indivíduo recupera sua supremacia, sua capacidade de realização, repousando na satisfação das suas necessidades solidariamente (FILHO; JÚNIOR, 2003). 


\section{O PODER SOCIAL DA MOEDA}

Enquanto que a "economia capitalista" serve para destruir hábitos e imbricar no modus operandi do sistema social, em contrapartida, a moeda social democratiza a sociedade pela participação na gestão da moeda por todos os usuários, bem como pela transparência administrativa das responsabilidades partilhadas, o que vêm a permitir o intercâmbio da continuidade das operações financeiras, que por sua vez tende a equacionar as demandas pendentes e as ofertas futuras quando da posse desse dinheiro. Como a moeda serve de meio de troca, a confiança entre os grupos respalda o valor da moeda. Além disso, seu caráter de "serviço público" serve para favorecer a circulação e a produção de mercadorias, contrapondo-se a qualquer especulação de lucro estéril, promovendo, ainda, uma cultura de bem-estar em face do seu papel não "lucrativo" uma vez que o trabalho não-remunerado exaure o proveito oriundo de qualquer tipo de especulação (SOARES, 2011).

Para além de um meio de troca, como fora apontado por Théret (2008), a moeda representa ao mesmo tempo um campo econômico, vista de um ângulo institucionalista como algo desconexo das pessoas; um campo político, enquanto sistemas e regras, que se reveste como uma espécie de canal entre as pessoas e as coisas; e, por fim, um campo simbólico, ao tomar a moeda como um símbolo que permite interações e significados que passam a ser compartilhados pelos indivíduos entre seus variados tipos de relacionamentos no âmbito financeiro. As moedas sociais são modelos circulantes em ambientes locais, restringindo-se, sua atuação, a um determinado território na maioria dos casos (RIGO; FILHO, 2017).

Assim como qualquer outro "equivalente universal de troca", a moeda social
deve cumprir (e tem condições para tanto) as funções de: a) medida de
valor/unidade de conta - facilita o acordo sobre os valores relativos das
diversas mercadorias; b) meio de pagamento - permite que os intercâmbios
ocorram diferidos no tempo, espaço e entre agentes distintos; c) reserva de
valor - permite, se a moeda social estiver sendo bem administrada, que seu
valor varie muito pouco, ou moderadamente, de tal forma que ela poderá
ser utilizada para fins de poupança (SOARES, 2011, p. 56).

Independente do exercício da intermediação financeira, as relações econômicas na comunidade estão baseadas em cooperação e solidariedade no sistema de pagamento (FREIRE, 2007). "Uma diferença importante entre a moeda social e o dinheiro oficial, é que qualquer um pode fazer uso dela na medida em que tenha algo para oferecer, como um produto ou serviço, dentro do espaço onde ela 
circula, no qual sua aceitação é voluntária (FAUSTINO; LISBOA, 2016). "Elas surgem, na economia solidária, de forma semelhante à criação do uso da moeda como alternativa ao escambo, nas trocas de produção do trabalho desenvolvido em empreendimentos solidários" (MIRANDA, 2008).

Segundo Rigo (2014) a importância da moeda social está presente na economia local de uma região por apresentar condições apropriada para a comunidade, uma vez que reorganiza a economia local pela dinamização e incentivo ao consumo nessas localidades, se tratando de uma moeda aceita única e exclusivamente no ciclo financeiro destas, sem conexão compulsória a moeda do país, "contribui para o estreitamento de laços de amizade, o uso de confiança nas relações comerciais, opera como ajuda mútua entre os integrantes, pretende dificultar o déficit socioeconômico e fomentar a construção de novos empreendimento internos" (DAMASCENO; GUEDES; JÚNIOR; SOUZA, 2016).

Ao implantar o uso de moedas sociais, segundo Rigo e Filho (2017), os Bancos Comunitários de Desenvolvimento Social estariam vivenciando junto à comunidade uma experiência baseada em laços sociais e relações de confiança, com base em uma analogia constituída no cenário mercadológico de bens e serviços e dos mecanismos de redistribuição quanto ao poder de compra por parte do indivíduo.

No Brasil, a Secretaria Nacional de Economia Solidária, tem procurado incentivar o surgimento de novos Bancos Comunitários de Desenvolvimento que são responsáveis pela emissão das moedas sociais, além de unir-se no engajamento pela criação de um marco que regule uma política de finanças solidárias no uso das moedas sociais no âmibito federal, estadual e municipal (NASCIMENTO, 2011).

A necessidade do elemento "confiança", parte menos do objeto em si, isto é, de um papel moeda, e mais da legitimidade do banco comunitário, quiçá dos mecanismos criados pelo banco para desenvolver a comunidade local. A partir da tríplice ação denominada dar-receber-retribuir, o exemplo de sucesso da Moeda Palmas, criada pelo Banco Palmas na década de 90, Rigo e Filho (2017) nos esclarece:

No que tange ao uso da moeda social, a ideia era sensibilizar os comerciantes a aceitarem a moeda e as pessoas a comprarem no bairro. Nota-se, neste processo, uma clara preocupação com a dimensão de pedagogia política em tais ações, apontando para processos de mudança 
de cultura política no local enquanto uma dinâmica de aprendizagem lenta e gradual (p. 177).

O caso da moeda Palmas é um dos vários exemplos de sucesso no tocante ao fomento social em comunidades, em questão, tem-se o Conjunto Habitacional Palmeiras na região Sul de Fortaleza-CE, iniciado por 1.500 famílias pobres transferidas, constituída inicialmente sem serviços de infraestrutura básica, tais como saneamento, água tratada, energia elétrica e escola. Por meio de insistências reivindicatórias por parte da comunidade, aos poucos, o Estado vai assumindo suas responsabilidades, mas não o suficiente para desenvolver uma rede de solidariedade entre os moradores (NASCIMENTO, 2011).

Figura 1 - Imagem Moeda Social Palmas

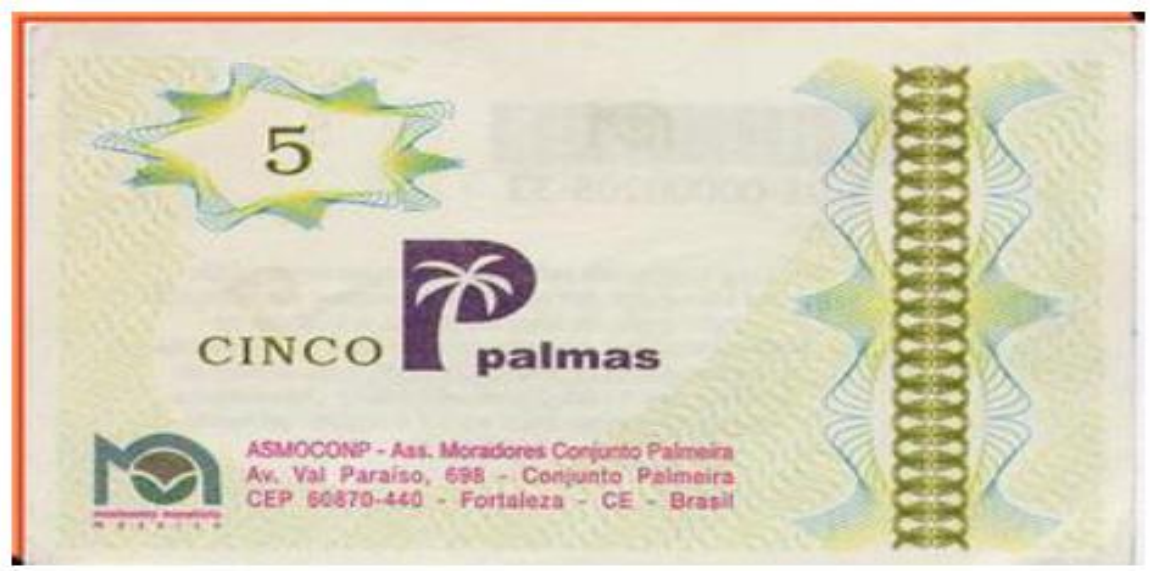

Fonte: Site Banco Palmas, 2018.

Em 1998 surge, na comunidade de Palmeiras, um banco popular de inclusão social, o Banco Palmas, com o propósito de garantir microcréditos para famílias a juros mais baixos, sem exigência de consultas cadastrais, comprovação de renda ou fiador, o que geralmente é exigido pelos bancos e que torna o acesso ao crédito ainda mais difícil (NASCIMENTO, 2011). No entanto, para alcançar seus objetivos a baixo custo e de forma sustentável, não esquecendo, ainda, da qualidade de vida dos moradores, vários programas criados pelo Banco Palmas: articulam-se com afinco a rede dos "Prosumidores", isto é, produtores e consumidores, a saber

Uma escola de capacitação, uma incubadora para mulheres em situação de risco, um laboratório de agricultura urbana, clubes de trocas com moda social, uma moeda própria que circula nos comércios do bairro, sistemas de feiras com os produtores locais e uma loja solidária (NASCIMENTO, 2011, p. 14). 
Nota-se que além da dimensão comunitária presente na moeda social, também existe uma dimensão pública, visto que o Estado não é capaz de preencher as lacunas deixadas pela economia de mercado. A moeda social "é uma opção inovadora que deve ser considerada, principalmente quando se acredita no negócio como forma de transformação social com compromisso comunitário" (SEBRAE, 2012). Dessa forma, ao desenvolver o local com a geração de emprego e renda, a construção desse "espaço público" torna-se coletiva e democrática (FRANÇAFILHO, 2006).

Para Faustino e Lisboa (2016) a experiência com a moeda social permite redescobrir as pessoas ocultas numa relação de troca, pois

\begin{abstract}
"todos somos prossumidores, ou seja: produtores e consumidores simultaneamente. Portanto, todos temos direito a uma participação no circuito monetário em condições justas e favoráveis ao desenvolvimento humano. O dinheiro deve circular. O dinheiro precisa circular na economia assim como o sangue no corpo, para manter a saúde de todos os sistemas integrados, pois se trata de fluxo (e não de acúmulo). Caso contrário, ele coagulará e gangrenará, com o consequente apodrecimento daquela parte" (p. 6).
\end{abstract}

Salienta-se, neste sentido, como a moeda social assume uma luta pela desigualdade social, presumindo o seu modo sustentável de circulação local, ao dialogar contextualmente com as manifestações concretas de um problema real enfrentado pelas sociedades contemporâneas a partir do capitalismo (NASCIMENTO, 2011).

Vejamos abaixo o quadro que demonstra uma comparação concisa entre as características da moeda social e as características da moeda nacional:

Quadro 1 - resumo da moeda social e da moeda nacional

\begin{tabular}{|c|l|l|}
\hline Elementos & \multicolumn{1}{|c|}{ Moeda Social } & \multicolumn{1}{c|}{ Moeda Nacional } \\
\hline Emissão & $\begin{array}{l}\text { Descentralizada, } \\
\text { coordenada pelos usuários. }\end{array}$ & $\begin{array}{l}\text { Centralizada, coordenada } \\
\text { pelos emitentes (Estado e } \\
\text { bancos privados). }\end{array}$ \\
\hline Funções & $\begin{array}{l}\text { Meio de pagamento, meio } \\
\text { de troca, reserva de valor. }\end{array}$ & $\begin{array}{l}\text { Reserva de valor, meio de } \\
\text { pagamento, meio de troca. }\end{array}$ \\
\hline Usos Econômicos & $\begin{array}{l}\text { Facilitar intercâmbios, } \\
\text { instrumento do } \\
\text { desenvolvimento, } \\
\text { instrumento de cooperação. }\end{array}$ & $\begin{array}{l}\text { Reter valor, instrumento } \\
\text { para acumulação de capital, } \\
\text { instrumento de } \\
\text { concorrência. }\end{array}$ \\
\hline Usos Sociais & $\begin{array}{l}\text { Recentralizar a economia no } \\
\text { homem, Estar acessível a } \\
\text { todos que precisem, ser }\end{array}$ & $\begin{array}{l}\text { Centralizar e potencializar } \\
\text { poder, ser instrumento de } \\
\text { hegemonia dos fins }\end{array}$ \\
\hline
\end{tabular}




\begin{tabular}{|c|l|l|}
\hline & $\begin{array}{l}\text { instrumento de maior } \\
\text { liberdade e exercício de } \\
\text { autonomia. }\end{array}$ & $\begin{array}{l}\text { econômicos, ser } \\
\text { instrumento de exclusão } \\
\text { social. }\end{array}$ \\
\hline Gestão & $\begin{array}{l}\text { Participativa, autônoma, } \\
\text { democracia participativa }\end{array}$ & $\begin{array}{l}\text { Delegada, heterônoma, } \\
\text { democracia representativa. }\end{array}$ \\
\hline Base para Aceitação & $\begin{array}{l}\text { Confiança mútua, } \\
\text { Continuidade, } \\
\text { Utilidade/necessidade }\end{array}$ & $\begin{array}{l}\text { Confiança intermediada pelo } \\
\text { Estado, continuidade, } \\
\text { valorização via escassez } \\
\text { administrativa. }\end{array}$ \\
\hline Padrão de Desenvolvimento & $\begin{array}{l}\text { Integral em construção } \\
\text { contínua. Precisa ser } \\
\text { socialmente discutido } \\
\text { porque não tem } \\
\text { mecanismos autoperpétuos. } \\
\text { Chega a ser cansativo em } \\
\text { sua necessidade de } \\
\text { participação integral dos } \\
\text { membros. }\end{array}$ & $\begin{array}{l}\text { Economicista e Teleológio, } \\
\text { em direção ao crescimento } \\
\text { das quantidades } \\
\text { exploradas/incorporadas, } \\
\text { porque a dinâmica dos juros } \\
\text { compostos exige a } \\
\text { concorrência via } \\
\text { quantidades. }\end{array}$ \\
\hline
\end{tabular}

Fonte: Soares (2011), p. 63.

Apreendemos do quadro acima que as operações realizadas por meio da moeda social são concebidas, distribuídas e geradas pelo próprio usuário. A relação mais transparente e direta nos permite olhar para além do trabalho, pois não se trata de uma finalidade do ato econômico, haja vista que o valor de troca e o valor de uso perdem seu sentido perante o incomensurável no vínculo entre as pessoas (FAUSTINO, LISBOA, 2016). "Além de eficiente ferramenta financeira, é um instrumento de construção de cidadania, que permite redefinir os conceitos de riqueza, solidariedade e responsabilidade social" (NASCIMENTO, 2011).

Apesar dos benefícios oriundos da moeda social, Soares (2011) nos alerta para uma punição em nível de isolamento entre aqueles que adotam a modalidade monetária. Para Soares, tendo em vista o cenário contemporâneo em que vivemos, ao adotar uma moeda diferente da implantada pelo Estado, os adotantes passam por uma espécie de rejeição pelos demais membros da sociedade os quais são não adotantes da moeda. Do ponto de vista do autor, ocorre uma limitação entre a moeda local e a moeda nacional, pois enquanto aquela tem o intercâmbio reduzido, por ser local; esta, por ser nacional, goza das institucionalidades tradicionais fortemente enraizadas, pensamento esse, inclusive, presente nos integrantes da comunidade que não adotam o uso da moeda social. 
Apesar de ser considerada relativamente nova no contexto da economia solidária, no Brasil, a moeda social, atualmente é produzida em mais de 104 tipologias nos pequenos e nos grandes centros urbanos, sendo a Secretaria Nacional de Economia Solidária - SENAES, gestor da vida dessas moedas (DAMASCENO; GUEDES; JÚNIOR; SOUZA, 2016).

\section{CAPITAL SOCIAL COMO A ORIGEM DE DISTRIBUIÇÃO SOCIAL}

O Capital Social é uma perspectiva interdisciplinar que busca compreender os agrupamentos humanos, suas causas, efeitos e consequências na dimensão da mediação digital. Esse processo comunicacional e relacional que constrói relações sociais que, por sua vez, vão integrar laços sociais entre os diversos atores (membros sociais). Essa troca existente de capital social e sua distribuição e, consequente redistribuição é um tipo de Capital Social.

O que vem a ser o Capital Social? constitui-se justamente no conteúdo das trocas sociais, que modelas a estrutura social, algo intangível no tocante a sua concretude, porém muito importante quando se trata das relações sociais, especialmente no objeto desse artigo.

Nesse caso, na perspectiva do artigo estudado acontece os dois tipos de nível de Capital Social descritos por Betolini e Bravo (2004): tanto no 1ำ nível no tocante ao relacional, normativo e cognitivo quanto ao $2^{0}$ nível (confiança no ambiente social e institucional).

Entre os principais autores que abordaram sobre o Capital Social e os valores abstratos destacam-se:

Quadro 2 - Conceitos de capital social

\begin{tabular}{|l|l|}
\hline \multicolumn{1}{|c|}{ FONTE } & \multicolumn{1}{|c|}{ CONCEITO } \\
\hline & "o conjunto de recursos atuais ou potenciais que são \\
colocados à posse de uma rede durável de relações mais ou \\
menos institucionalizadas pelo convívio e pelo \\
Bourdieu (1980, p. \\
2)
\end{tabular}




\begin{tabular}{|c|c|}
\hline & $\begin{array}{l}\text { percebidas pelo observador, por outros e por eles mesmos), } \\
\text { mas são também unidos por laços permanentes e úteis"; }\end{array}$ \\
\hline $\begin{array}{l}\text { Coleman (1988, p. } \\
98)\end{array}$ & $\begin{array}{l}\text { "o capital social é definido por sua função. Ele não é uma } \\
\text { entidade individual, mas uma variedade de diferentes } \\
\text { entidades com dois elementos comuns: todas elas consistem } \\
\text { em algum aspecto das estruturas sociais e elas facilitam certas } \\
\text { ações dos atores - sejam pessoas ou atores corporativos - } \\
\text { dentro da estrutura"; }\end{array}$ \\
\hline $\begin{array}{l}\text { Putnam (2002, p. } \\
\text { 177) }\end{array}$ & $\begin{array}{l}\text { "características da organização social, como confiança, } \\
\text { normas e sistemas, que contribuam para aumentar a eficiência } \\
\text { da sociedade, facilitando as ações coordenadas"; }\end{array}$ \\
\hline $\begin{array}{l}\text { Fukuyama }(1996, \\
\text { p. } 41 ; 2000, \text { p. } 28)\end{array}$ & $\begin{array}{l}\text { "uma capacidade que decorre da prevalência de confiança } \\
\text { numa sociedade ou em certas partes dessa sociedade"; "um } \\
\text { conjunto de valores ou normas informais, comuns aos } \\
\text { membros de um grupo, que permitem a cooperação entre } \\
\text { eles"; }\end{array}$ \\
\hline $\begin{array}{l}\text { Nahapiet } \quad \text { e } \\
\text { Ghoshal (1998, p. } \\
\text { 243) }\end{array}$ & $\begin{array}{l}\text { "a soma de recursos atuais ou potenciais imersos nas, } \\
\text { disponíveis pelas, e derivados das redes de relacionamentos } \\
\text { pertencentes a um indivíduo ou unidade social" }\end{array}$ \\
\hline
\end{tabular}

Fonte: Melo, Regis \& Bellen (2005)

\section{PROCEDIMENTOS METODOLÓGICOS DA PESQUISA}

O tipo de pesquisa realizada foi a pesquisa bibliográfica, utilizando-se também materiais disponíveis em meios eletrônicos como a rede mundial de computadores (internet) (Vergara: 2005; p. 46). Desenvolvendo um sistema conceitual sobre a moeda social e a economia solidária. O método a ser utilizado será o dialético, no que se refere a sua primeira lei da passagem da quantidade para a qualidade (Konder: 2004; p. 58). Onde a mudança das coisas não acontece no mesmo ritmo, às vezes passa por ritmos bastante lentos; outras vezes por "saltos" (modificações radicais). 


\section{CONSIDERAÇÕES FINAIS}

Como vimos, a moeda social tem servido como um instrumento de desenvolvimento social eficiente, por ter se tornado uma mola propulsora do real sentido econômico e social, ao contribuir para o fortalecimento econômico local com a geração de renda, produção colaborativa e poder de consumo.

Dessa forma, o desenvolvimento sustentável de uma comunidade, através da economia solidária, é tomado como uma tecnologia social que instrumentaliza os recursos escassos, para promover trabalho e renda em territórios de alto grau de vulnerabilidade e exclusão social, compreendendo-se, a economia solidária, como uma inovadora alternativa de trabalho e de renda, além de uma resposta a inclusão social (NASCIMENTO, 2011).

Não obstante, urge um novo modelo bancário, os bancos comunitários, despretensiosos quanto ao lucro financeiro e otimistas quanto ao lucro social, acima de tudo, ajudam as comunidades a construírem um muro de proteção para fortalecer o valor da moeda empregada e para materializar uma iniciativa na qual se intenciona recuperar as economias mais empobrecidas e, ao mesmo tempo, desenvolver o local.

A política pública de economia solidária, num país como o Brasil, enfrenta diversos desafios. Estes provêm, em grande parte, da pobreza do público engajado na construção de uma "outra economia" que se caracteriza pela posse coletiva dos meios de produção pelos trabalhadores, pela autogestão praticada de acordo com regras democráticas pelos mesmos trabalhadores e pela repartição justa entre os sócios, ao ver da maioria destes, dos ganhos obtidos graças ao trabalho de todos (BANCO PALMAS, 2013, p. 35).

Quiçá, um desses desafios deva-se a dificuldade do acesso ao crédito e financiamento, principalmente as classes menos favorecidas socialmente, tendo em vista as exigências postas pelos bancos aos "marginalizados" ao tentarem o acesso a uma linha de crédito. No entanto, os bancos comunitários assumem o papel de "agente" de política pública, rompendo com as barreiras do sistema econômico dominante, ao abrir mão de garantias, em defesa do social, garantias essas que não passam de modelos promovedores de desigualdade e desumanidade.

Tratar-se-ia, a economia solidária, de um novo modo de produção, tendo como princípios básicos as prioridades coletivas e/ou associadas do capital, além do direito a liberdade individual. $O$ resultado natural desses princípios repousa na 
solidariedade e igualdade, uma vez que as aplicações desses princípios unificam os possuidores do capital por igual (SINGER, 2002).

\section{REFERÊNCIAS}

BLANC, J. (1998): Les monnaies paralleles: evaluation et enjeux theoriques du phenomene. Revue d'Economie Financière, n. 49, p. 81-102, set. 1998.

BERTOLINI, Sandra e BRAVO, Giácomo. Social Capital, a Multidimensional Concept. 2004.2 Disponível em <http://www.ex.ac.uk/shipss/politics/research/socialcapital/other/bertolini.pdf> Acesso em 25/03/2018.

BOURDIEU, P. Le capital social. Actes de la recherche en sciences socieales, v. 31, p. 2-3, 1980.

BRAUDEL, Fernand. Civilização Material, Economia e Capitalismo - Século XVXVIII - Volume 2: os jogos das trocas. São Paulo: Martins Fontes, 2005.

CERTEAU, Michel de. A invenção do cotidiano: 1. Artes de fazer. Petrópolis: Vozes, 1994.

COMMAILLE, Jacques. La famille, la fin de la loi? Futuribles, n. 153, p. 79-88, 1991.

DAMASCENO, Celimar Reijane Alves, et al. Análise dos projetos em funcionamento de moeda social como indutora da inclusão social e desenvolvimento local, num contexto da economia solidária. In: V Congresso em Desenvolvimento Social - Estado, Meio Ambiente e Desenvolvimento. 29 de junho a 1 de julho de 2016.

DURKHEIM, Émile. Leçons de sociologie. Paris: PUF, 1950.

FAUSTINO, Andrea Viana; LISBOA, Armando de Melo. Trocas solidárias, moeda e espiritualidade. Princípios da Economia Solidária. Disponível em:< http://www.grapinar.com.br/gaia/social/ecosol/economia_solidaria.pdf >. Acesso em 15 de janeiro de 2018.

FILHO, Genauto Carvalho de França; RIGO, Ariádne Scalfoni. O paradoxo das Palmas: análise do (des)uso da moeda social no "bairro da economia solidária". Cad. EBAPE.BR, v. 15, no 1, Artigo 10, Rio de Janeiro, Jan./Mar .2017.

FRANÇA, Filho; SILVA, Júnior. Fato Associativo e economia solidária: a experiência do Banco Palmas no Ceará, 2003. 
FRANÇA-FILHO, G.C; LAVILLE, J.L., 2006, "Economia Solidária - uma abordagem internacional”, Rio Grande do Sul, Ed. UFRGS.

FREIRE, M. V., "Moedas sociais: contribuições para a sua constituição jurídica”, Disponível em:

<http://economialegal.wordpress.com/2007/08/24/moedas-sociais-contribuicoespara-a-suaconstrucao-juridica/ >. Acesso em 19.09.2008.

FREYRE, Gilberto. Casa-grande \& Senzala: Formação da Família Brasileira sob o regime da economia patriarcal. Rio de Janeiro: Ed. José Olympio, 1987.

FUKUYAMA, F. A grande ruptura: a natureza humana e a reconstituição da ordem social. Rio de Janeiro: Rocco, 2000.

Janeiro: Rocco, 1996.

Confiança: as virtudes sociais e a criação da prosperidade. Rio de

KONDER, Leandro. O que é dialética. 2ª edição. São Paulo: Brasiliense, 2004

MACIEL, M. L. Capital Social e empreendedorismo local. Disponível em: http://www.redesist.ie.ufrj.br/nt_count.php?projeto=nt33\&cod=24 Acessado em: 07 de

novembro de 2008.

MANDEL, Ernest. A Formação do Pensamento Econômica de Karl Marx. Rio de Janeiro: Zahar, 1968.

MARX, Karl. Formações Econômicas Pré-Capitalistas. 4ª edição. Rio de Janeiro: Paz e Terra, 1985.

MELO, H. A. Economia solidária e a reconstituição das alternativas de sobrevivência. Bahia Análise \& Dados, v. 14, n. 3, p. 521-534, dez. 2004.

MELO, Paulo Thiago Nunes Bezerra de; REGIS, Helder Pontes; BELLEN, Hans Michael Van. Princípios epistemológicos da teoria do capital social na área da administração. Cadernos EBAPE.BR (FGV), v. 13, p. 136-164, 2015.

MIRANDA, Guacira Quirino. Painel de moedas sociais. $4^{\underline{a}}$ Semana do Servidor e $5^{\text {a }}$ Semana Acadêmica. 2008 - UFU.

MOEDA PALMAS. Banco Palmas. Disponível em:< http://www.bancopalmas.org.br/oktiva.net/1235/secao/10043>. Acesso em 12 de março de 2018.

NAHAPIET, J.; GHOSHAL, S. Social capital, intellectual capital, and the organizational advantage. Academy of Management Review, v. 23, n. 2, p. 242266, 1998. 
NASCIMENTO, Arilson Martins do. Moeda Palma e o Desenvolvimento sustentável do Conjunto Palmeiras através da economia solidária. 2011, 131 p. Dissertação (Mestrado Profissional em Economia) - CAEN, Fortaleza/CE.

Núcleo de Economia Solidária - NESOL-USP. Banco Palmas 15 anos: resistindo e inovando. Instituto Palmas - São Paulo: A9 Editora, 2013.

PUTNAM, R. D. Comunidade e Democracia: a experiência da Itália moderna. 2. ed. Rio de Janeiro: FGV, 2002.;

RIGO, Ariádne Scalfoni. Moedas sociais e bancos comunitários no Brasil: aplicações e implicações, teóricas e práticas / Ariádne Scalfoni Rigo - 2014.

SINGLY, François de. Sociologia da Família Contemporânea. Lisboa: Edições Texto \& Grafia, 2012;

SOARES, Claudia Lucia Bisaggio. A moeda social e a economia solidária no brasil: instrumentos para um novo padrão de desenvolvimento? Revista Orbis Latina, vol.1, n¹, janeiro-dezembro de 2011. ISSN 2237-6976.

SEBRAE. Meios de Pagamentos Digitais. Brasília: DF, 2012.

SINGER, Paul. (2002): Introdução à economia solidária. Fundacao Perseu Abramo: Sao Paulo.

THÉRET, B. Os três estados da moeda: abordagem interdisciplinar do fato monetário. Campinas, Economia e Sociedade, v. 17, n. 1 (32), p. 1-28, abr. 2008.

THOMPSON, Edward P. A Formação da Classe Operária Inglesa, 1: A árvore da liberdade. São Paulo: Paz e Terra, 2011.

VERGARA, Sylvia Constant. Projetos e relatórios de pesquisa em administração. 6. ed. São Paulo: Atlas, 2005. 